\title{
Electron Microscopic Studies on the Palpi of Cybister fimbriolatus fimbriolatus (Say)*
}

\section{Examination of the Cuticular Surfaces by Means of the Scanning and Transmission Electron Microscopes}

\author{
Fumioki Yasuzumi and Sakmori Yamaguchi \\ Department of Anatomy, Nara Medical University (Director: Prof. G. Yasuzumi, M. D.) \\ Gerald H. Johnson \\ Department of Wildlife and Fisheries, School of Natural Resources, University \\ of Michigan (Director: Prof. John E. Bardach, Ph. D.)
}

Received March 1, 1971

Summary. The maxillary palpi of the predaceous diving beetle Cybister fimbriolatus fimbriolatus Say were observed by transmission and scanning electron microscopy. Scanning electron microscopy shows at least two types of sensilla at the tip of palp, which are referred to as "circumvallate and naked sensilla". The former are innervated with outer segments of distal processes of sensory cells, but the latter are provided only with chitin and cuticular substances.

Key-Words: Maxillary palpi - Circumvallate sensilla - Naked sensilla - Sensory cells - Cybister fimbriolatus (beetle).

A large number of studies necessary for understanding insect sense organs have been made by electron microscopy (e.g., Adams, 1961; Slifer, 1961; Slifer and Sehkon, 1961; Stürckow, 1962; Larsen, 1962, 1963; Thurm, 1964; Slifer and Sehkon, 1964a-c; Slifer et al., 1964; Peters, 1965; Boeckh et al., 1965; Ivanov, 1966; Thurm, 1966; Stürckow, 1967; Ernst, 1969; Tominaga et al., 1969 ; Ivanov, 1969 ; Dallai, 1970; Altner et al., 1970). However, the maxillary palp of the predaceous diving beetle Cybister fimbriolatus fimbriolatus Say has never been observed in detail by electron microscopic procedures, so far as the present authors are aware.

Although the transmission electron microscope contributes to analyzis of the fine structure of tissue cells, sections used in transmission electron microscopy are remarkably thin and represent only a small sample of the total tissue. Therefore, they may not suffice in themselves to provide an understanding of the three dimensional organization of the tissue. Biologically significant features, such as the insect palp surfaces, especially their tip surfaces, are so complex that their orientation and basic structures do not emerge from study of sections alone. Our present incomplete knowledge of the structure of insect sense organs seems to

* This work was supported by Grant NB 04687 from the National Institutes of Health of the United States of America.

We wish to express our gratitude to Prof. H. Stanley Bennett, Laboratories for Reproductive Biology, School of Medicine, University of North Carolina, Prof. G. Yasuzumi, Electron Microscope Research Laboratory, Department of Anatomy, Nara Medical University, and Prof. John E. Bardach, Department of Wildlife and Fisheries, School of Natural Resources, University of Michigan, for their valuable advice to the present work. 
derive in part from inability of sectioning techniques to reveal features of the whole organ. Scanning electron microscopy permits examination of the surface morphology and thus reveals important aspects of the whole organ.

The present study attempts to clarify the structural details of the surfaces of maxillary palpi of the predaceous diving beetle by scanning and transmission electron microscopes.

\section{Material and Methods}

Techniques for Scanning Electron Microscopy: A pair of palpi of the predaceous diving beetle $C y$ bister fimbriolatus fimbriolatus Say were carefully removed from their basal attachment. They were fixed with $6.25 \%$ glutaraldehyde for 1 hour at $4^{\circ} \mathrm{C}$, and subsequently with $1 \%$ osmium tetroxide for 1 hour at $4^{\circ} \mathrm{C}$. Each fixative was adjusted to $\mathrm{pH} 7.2$ with $0.1 \mathrm{M}$ sodium cacodylate buffer. The fixed specimens were for 2 weeks stored in $70 \%$ ethanol solution. After allowing the ethanol to dry in air, the specimens were coated with a conductive layer of carbon 100-200 $\AA$ thick followed by a layer of gold of equal thickness in a vacuum evaporator. The specimens were examined in a Hitachi scanning electron microscope, model HSM-2, at an accelerating voltage of $25 \mathrm{kV}$.

Techniques for Transmission Electron Microscopy: The specimens fixed as described were dehydrated in a series of increasing concentrations of ethanol solutions and embedded in Epon 812 (Luft, 1961). Sections were eut with an LKB ultrotome using glass knives, mounted on Formvar-coated specimen grids and stained by the lead citrate method of Reynolds (1963). These sections were examined in a Hitachi electron microscope, model HU-11D-S or HU-12 at an accelerating voltage of $75-100 \mathrm{kV}$.

\section{Observations}

The maxillary palp of the present material consists of four segments, in which the distal segment measuring approximately $1.0 \mathrm{~mm}$ in length and $0.3 \mathrm{~mm}$ in maximal width, but the other ones 0.5 to $0.7 \mathrm{~mm}$ in length and $0.37 \mathrm{~mm}$ in maximal width (Fig. 1). It is covered with the chitinous cuticular elements which are made up of a set of hexagonal plates interlocking regularly with one another (Fig. 3). A small number of microsetae are found, each being inserted in a punctule. It is noticed that the seta is often truncated in several heights. The microseta is observed isolated at several points (Figs. 1, 2, 4), but occasionally in a group, each having an individual punctule. It looks to be antenna to catch electro-magnetic waves (Fig. 3).

The surfaces of palpi are relatively smooth except for the presence of microsetae, while the tip of the distal segment is not always smooth, it is rather concavo-convex (Fig. 4). On the surfaces one can discern several types of sensilla basiconica, most of them near the tip of palp (Fig. 5). One can recognize at least two types; some surrounded by a thick circular wall, some not. The former are referred to as "circumvallate sensilla", and the latter as "naked sensilla". Amongst the circumvallate sensilla, smaller constituent structures vary in the shape, size and number. Some sensilla are flame-like in shape, being surrounded by a deep, circular furrow, around which is a wall. Others display several small projections surrounded by a similar wall and moat (Fig. 6).

In sections it is possible to observe that the outer segments of distal processes of sensory cells extend into the central projection of the circumvallate sensillum (Fig. 8). Such a structure can not be seen in the naked sensillum which is provided only with dense chitin and less dense cuticular elements, but which do 

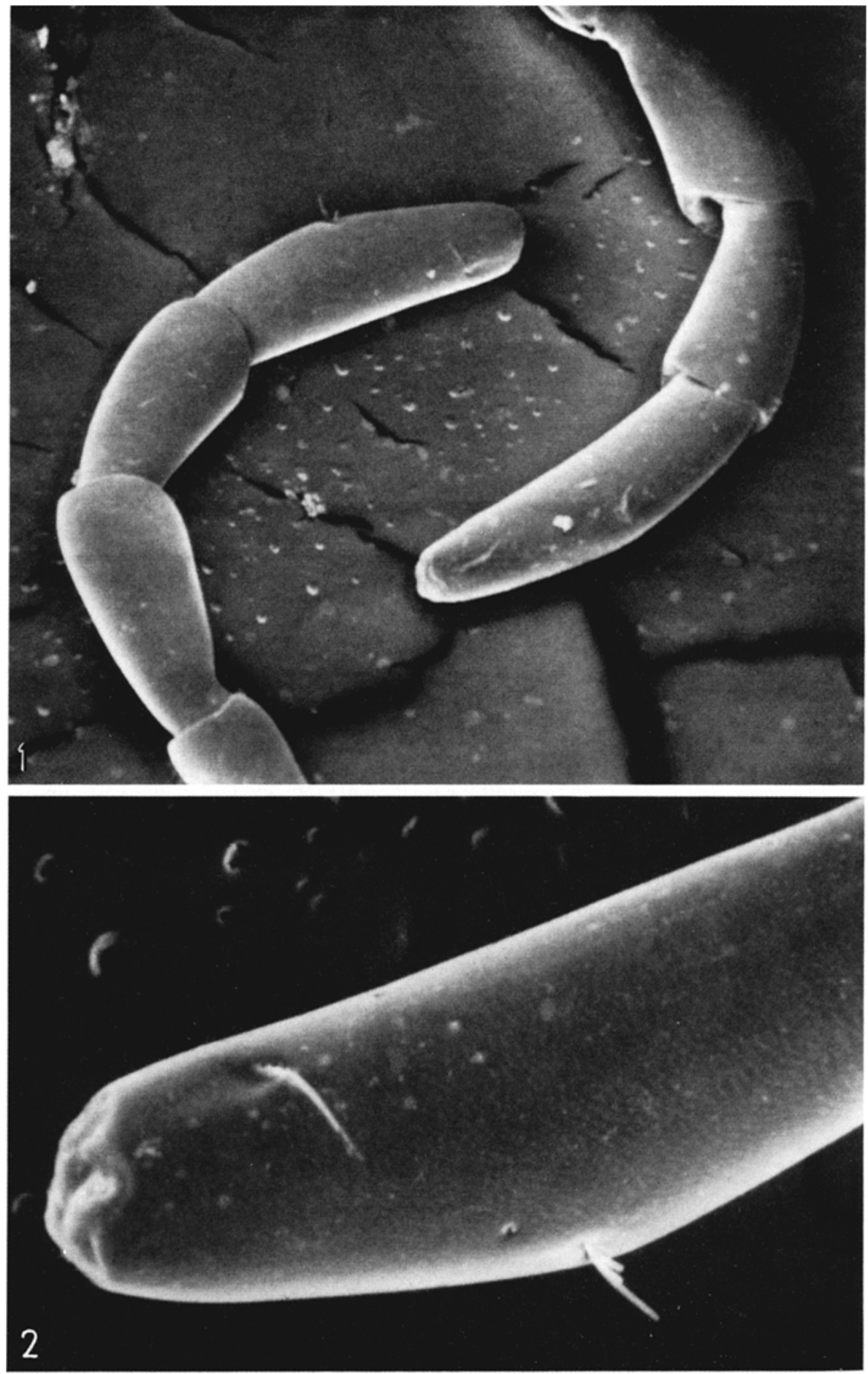

Figs. 1 and 2 


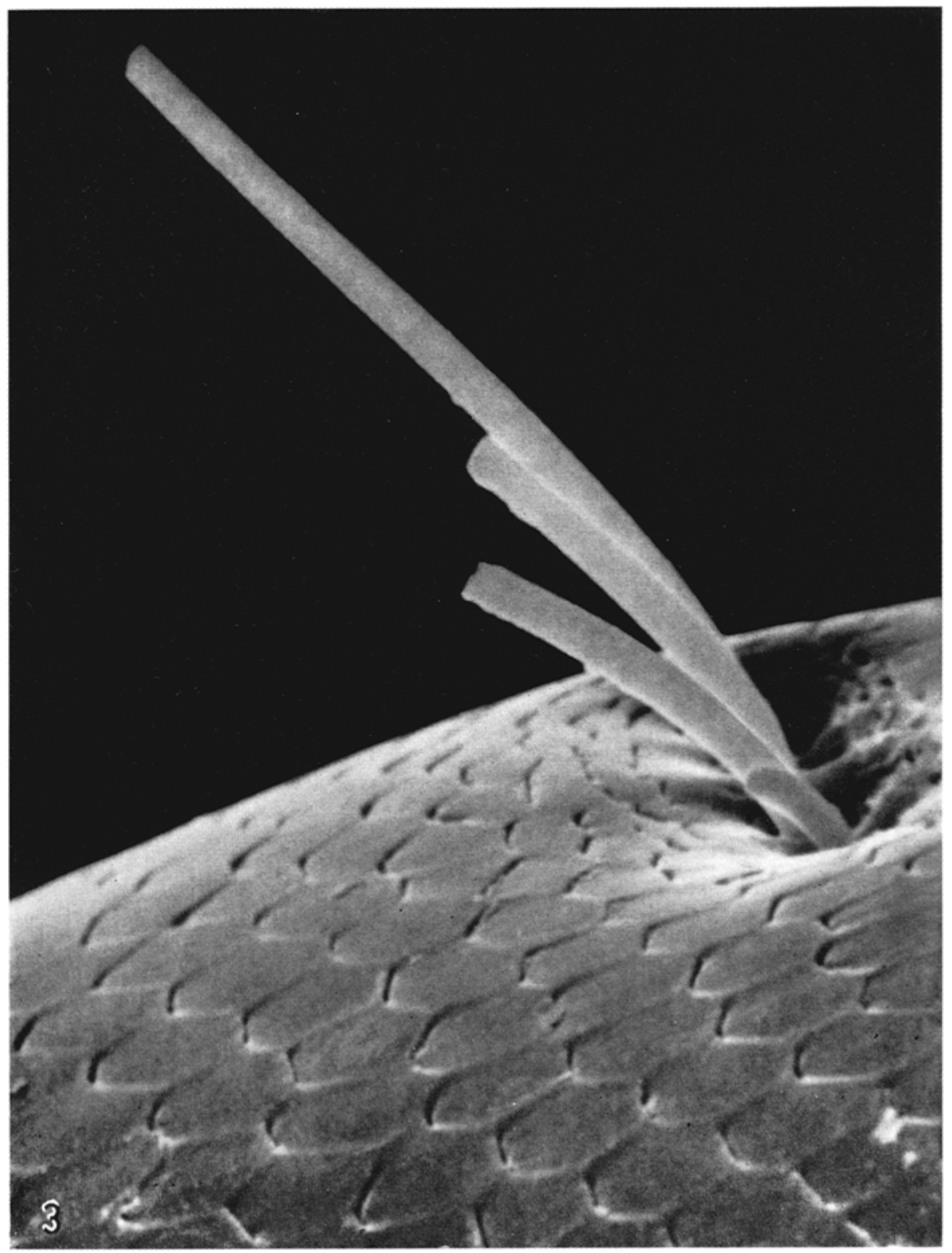

Fig. 3. Four microsetae different in length, each having individual punctule. The cuticular surface is covered with a set of plates showing a hexagonal appearance. $\times 1400$

Fig. I. Scanning electron micrograph of a pair of the maxillary palpi of the predaceous diving beetle, each consisting of four segments. $\times 49$

Fig. 2. Enlarged micrograph of one of the distal segments in Fig. 1, showing microsetae and an uneven surface of the tip of palp. $\times 140$ 

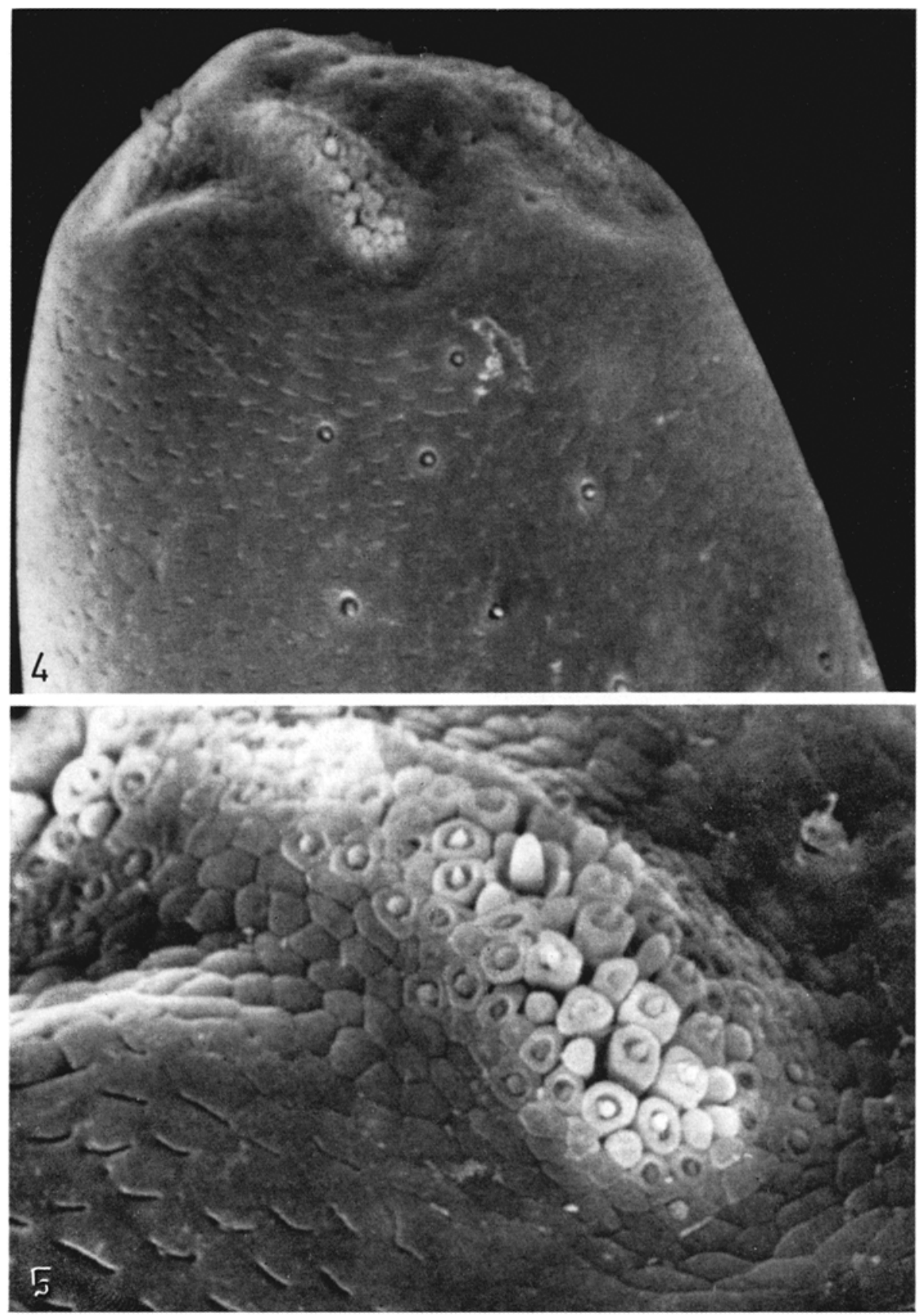

Fig. 4. The tip surface of palp is markedly uneven. The microsetae truncated at their apices are visible in about eight punctules. $\times 480$

Fig. 5. A part of the tip of palp. Numerous papillar structures are visible in a group. $\times 1400$ 


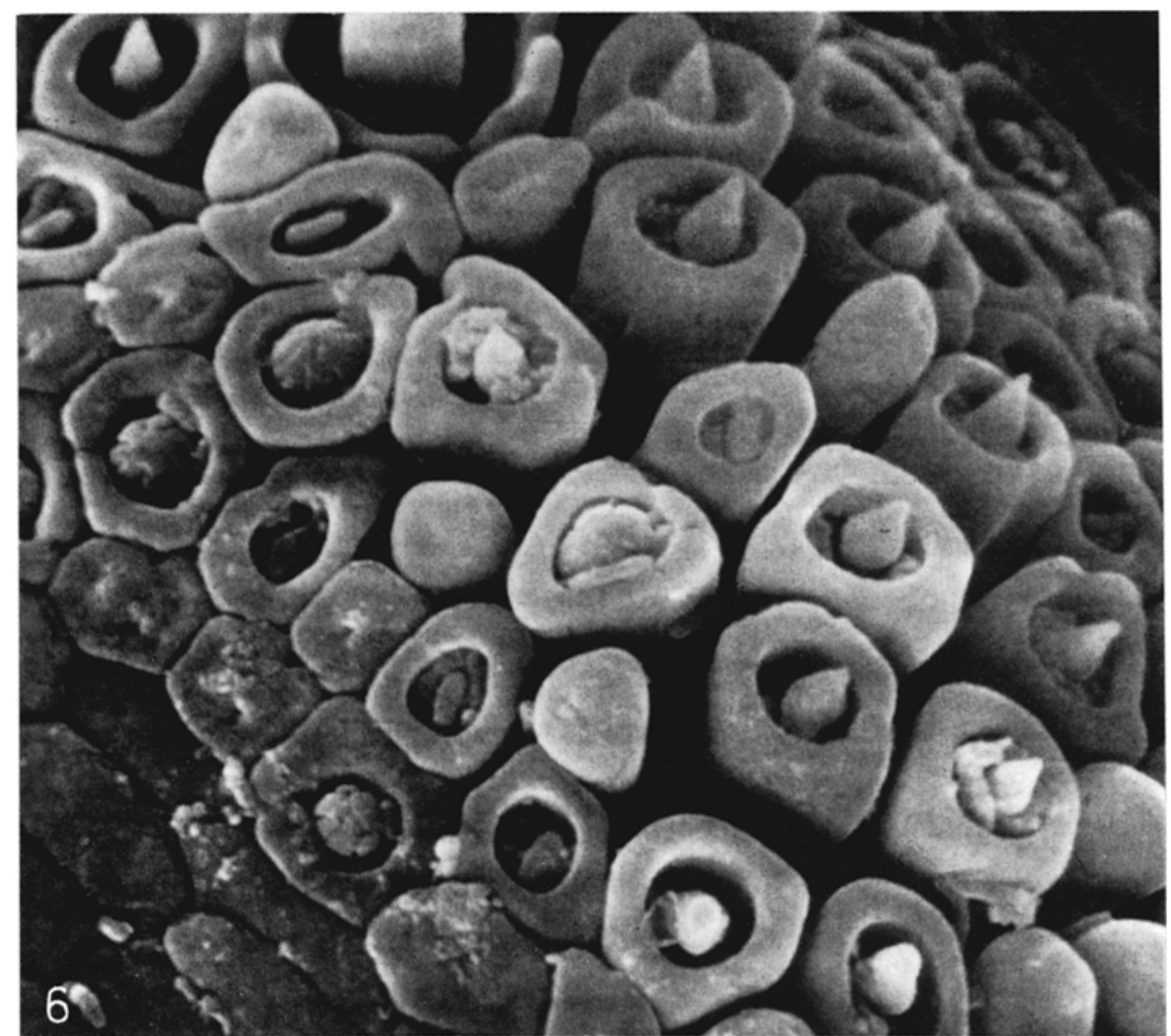

Fig. 6. The tip of palp is covered compactly with sensilla basiconica which are differentiated at least into two varieties: circumvallate and naked. $\times 4500$

not display any cellular ones (Fig. 7). The wall surrounding the circumvallate sensillum is approximately $0.7 \mu$ thick and consists of a dense, homogeneous chitinous material bounded by a less dense, lamellar cuticular layer. A member of the epidermal cell complex (Larsen, 1963), the trichogen cell, is observed just beneath the cuticular layer (Fig. 8).

\section{Discussion}

The scanning electron microscope provides an excellent opportunity to study the structure of large pieces of insect sense organs within a wide range of magnification at a good resolution. It is possible to investigate both natural surfaces as well as those artificially produced by preparing techniques: for example, some sensilla are flame-like in shape, being surrounded by a deep, circular furrow around which is a wall; others display several small projections surrounded by similar walls and moats. Such multiple features may be due to artifacts of preparative techniques such as fixation, dehydration, air drying and others.

Since the scanning electron microscope provided three-dimensional pictures of the palpi of the predaceous diving beetle, it was possible to obtain reconstructions 

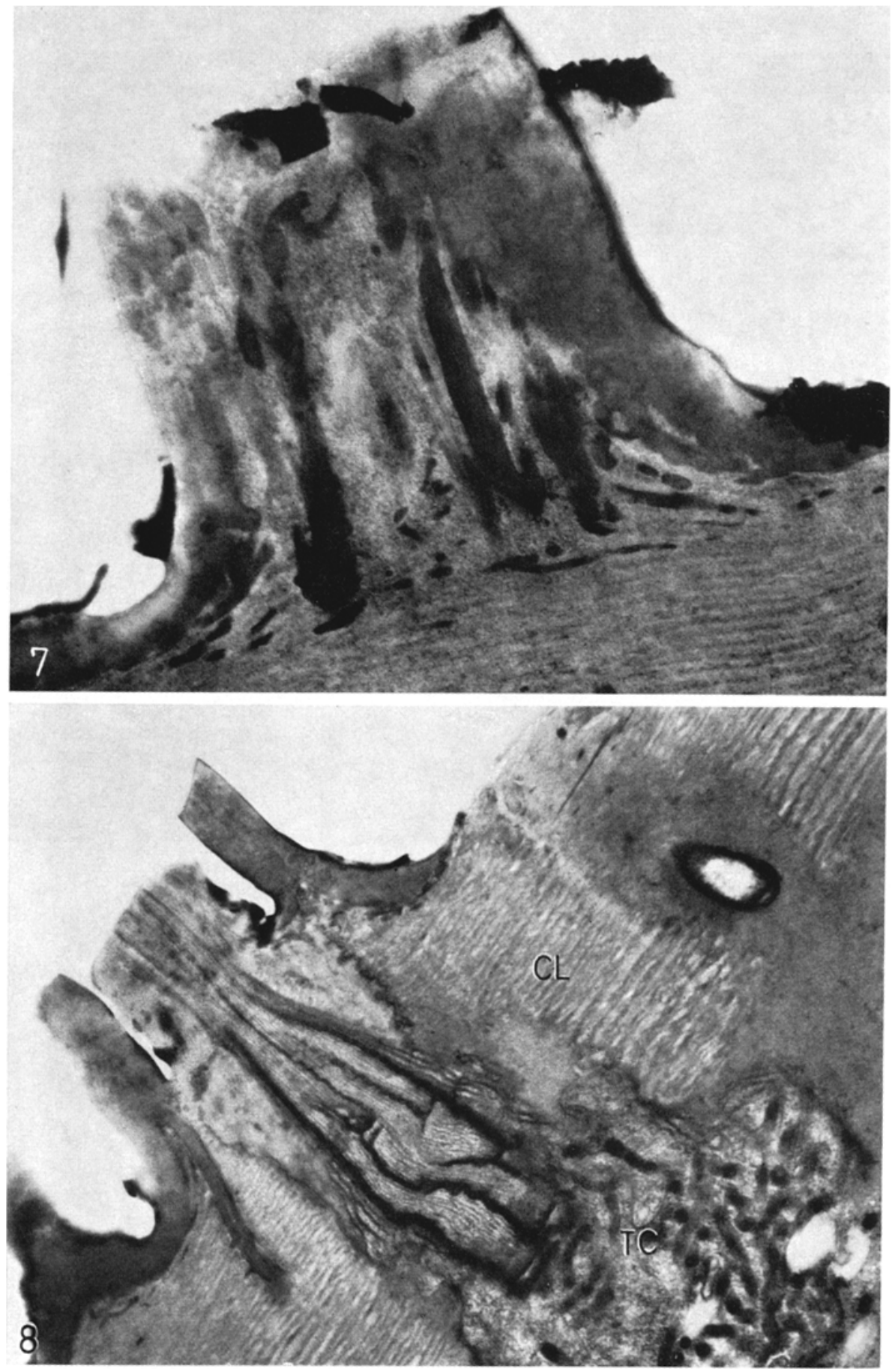

Fig. 7. A longitudinal section through a sensillum without wall. It is covered with a dense chitin layer, and composed of chitin and cuticular elements. The lamellar cuticular layer is situated beneath the sensillum. $\times 20000$

Fig. 8. An oblique longitudinal section through a circumvallate sensillum which is surrounded by a deep furrow and a dense wall. At least four outer segments of distal processes of the sensory cells are enclosed in the cuticular sheath. The trichogen cell $(T C)$ containing a large number of dense mitochondria and vacuoles is encountered under the cuticular layer $(C L)$. 
from pictures taken by transmission electron microscopy. It is believed that these two techniques present together excellent possibilities for structural analysis of biological tissue.

Recently, the ultrastructural organization of the chemoreceptive antennal sensillum of the beetle Acilius sulcatus was observed by transmission microscopy (Ivanov, 1969). The ultrastructure of the circumvallate sensillum observed in the present material is very similar to that of Acilius sulcatus. More recently, the postantennal sensillum of the collembola was studied by transmission electron microscopy by Altner et al. (1970), and the cuticular structure of the head and abdomen of such an insect by scanning electron microscopy (Dallai, 1970) separately. It is impossible to pursue a relationship between two kind pictures taken by different electron microscopic techniques. A characteristic insertion of microsetae observed in the collembola (Dallai, 1970) was never seen in the maxillary palp of the present material.

Scanning electron microscopy showed for the first time at least two types of sensilla at the tip of the maxillary palp, circumvallate and naked sensilla. The former were provided with outer segments of distal processes of sensory cells, but the latter only with chitin and cuticular substances. Accordingly, the latter may function as an apparatus for supporting the innervated circumvallate sensilla.

Combined experiments with electron microscopic and electrophysiological procedures may reveal more structural and functional details than could be recognized by each procedure respectively. Such results will be published elsewhere in near future.

\section{References}

Adams, J. R.: The location and histology of the contact chemoreceptors of the stable fly Stomoxys calcitrans L. Doctoral Diss. New Brunswick (New Jersey): Rutgers University 1961.

Altner, H., Ernst, K.-D., Karuhize, G.: Untersuchungen am Postantennalorgan der Collembolen (Aptrygota). I. Die Feinstruktur der postantennalen Sinnesborste von Sminthurus fuscus (L.). Z. Zellforsch. 111, 263-285 (1970).

Boeckh, J., Kaissling, K. E., Schneider, D.: Insect olfactory receptors. Cold Spr. Harb. Symp. quant. Biol. 30, 263-280 (1965).

Dallai, R.: Investigations on Collembola. X. Examination of the euticle in some species of the tribe Sminthurini Börner, 1913, by means of the scanning electron microscope. Monitore zool. ital. 4, 41-53 (1970).

Ernst, K.-D.: Die Feinstruktur von Riechsensillen auf der Antenne des Aaskäfers Necrophorus (Coleoptera). Z. Zellforsch. 94, 72-102 (1969).

Ivanov, V. P.: Ultrastructural organization of chemoreceptive antennal sensilles of the beetle Acilius sulcatus. J. evolutionary Biochem. Physiol. (Moscow) 2, 462-472 (1966).

- The ultrastructure of chemoreceptors in insects. Trud. Vsesoyuz. Entomol. Obshch. 53, 301-333 (1969). [Russian J.].

Larsen, J. R.: The fine structure of the labellar chemosensory hairs of the blowfly, Phormia regina Meig. J. Insect Physiol. 8, 683-691 (1962).

- Fine structure of the interpseudotracheal papillae of the blowfly. Science 139, 347 (1963).

Luft, I. H.: Improvements in Epoxy resin embedding methods. J. biophys. biochem. Cytol. 9, 409-414 (1961).

Peters, W.: Die Sinnesorgane an den Labellen von Calliphora erythrocephala MG. (Diptera). Z. Morph. Okol. Tiere 55, 259-320 (1965).

Reynolds, E. S.: The use of lead citrate at high $\mathrm{pH}$ as an electron opaque stain in electron microscopy. J. Cell Biol. 17, 208-212 (1963). 
Slifer, E. H.: The fine structure of insect sense organs. Int. Rev. Cytol. 11, 125-159 (1961).

- Sehkon, S. S.: Fine structure of the sense organs on the antennal flagellum of the honey bee, Apis mellifera Linnaeus. J. Morph. 109, 35I-381 (1961).

- - Fine structure of the thin-walled sensory pegs on the antennae of a beetle, Popilius disjunctus (Coleoptera: Passalidae). Ann. entomol. Soc. Amer. 67, 541-548 (1964a).

- The dendrites of the thin-walled olfactory pegs of the grasshopper (Orthoptera, Acrididae). J. Morph. 114, 393-410 (1964 b).

- - Fine structure of the sense organs on the antennal flagellum of a flesh fly, Sarcophaga argyrastoma R.-D. (Diptera, Sareophagidae). J. Morph. 114, 185-208 (1964c).

- - Lees, A. D.: The sense organs on the antennal flagellum of aphids (Homoptera), with special reference to the plate organs. Quart. J. micr. Sci. 105, 21-29 (1964).

Stürckow, B.: Ein Beitrag zur Morphologie der labellaren Marginalborsten der Fliegen Calliphora und Phormia. Z. Zellforsch. 57, 627-647 (1962).

- Occurrence of a viscous substance at the tip of the labellar taste hair of the blowfly. In: Olfaction and Taste, edit. by Hayashi, T., vol. 2, p. 707-720. Oxford: Pergamon Press, Inc. 1967.

Thurm, U.: Mechanoreceptors in the cuticle of the honey bee: Fine structure and stimulus mechanism. Science 145, 1063-1065 (1964).

- An insect mechanoreceptor. Part 1: Fine structure and adequate stimulus. Cold Spr. Harb. Symp. quant. Biol. 30, 75-82 (1966).

Tominaga, Y., Kabuta, H., Kuwabara, M.: The fine structure of the interpseudotracheal papilla of a fleshfly. Annot. zool. jap. 42, 91-104 (1969).

\section{Fumioki Yasuzumi}

Electron Microscope Research Lab.

Dept. of Anatomy

Nara Medical University

Kashihara City, Nara 634

Japan
Gerald H. Johnson

Dept. of Wildlife and Fisheries

School of Natural Resources

University of Michigan

1006 Natural Resources Building

Ann Arbor, Michigan 48104

U.S.A. 